\title{
DIFICULDADES PARA A IMPLEMENTAÇÃO DE PROJETOS PARA A PRODUÇÃO DE ALVENARIA: UM ESTUDO DE CASO
}

\author{
Cássia Villani Corrêa \\ Arquiteta, Mestre em Engenharia de Produção, Diretora \\ da CJ Arquitetos Associados - \\ cjarquitetos@cjarquitetos.com.br \\ Paulo R. P. Andery \\ Engenheiro, Doutor em Engenharia, Professor do \\ Programa de Pós-Graduação em Construção Civil da \\ Universidade Federal de Minas Gerais - \\ paulo@demc.ufmg.br
}

\section{RESUMO}

As pressões pela redução dos custos e melhoria da qualidade na construção de edifícios têm feito que as empresas construtoras, talvez de uma forma lenta e gradual, voltem sua atenção para a implementação de métodos e ferramentas que propiciem uma racionalização das atividades construtivas nos canteiros de obras. Uma dessas possibilidades é a contratação e desenvolvimento de projetos para a produção, em especial no caso de alvenarias de vedação.

Embora a literatura recente apresente vários estudos sobre o desenvolvimento e utilização desses projetos, são ainda escassos os trabalhos que focam as dificuldades para a implementação dos mesmos, do ponto de vista da atividade projetual. Nesse contexto, o presente trabalho propõe uma análise qualitativa das dificuldades identificadas na execução desses projetos, por meio de estudos de caso. Especial atenção é dada a análise de registros de incompatibilidades mais freqüentes que ocorrem nos projetos de produto (arquitetônico e complementares), e que impactam no desenvolvimento dos projetos de produção de alvenaria. São levantados problemas relativos a compatibilização de projetos ocorridos em dez empreendimentos distintos, de empresas que utilizaram o sistema de racionalização de alvenaria. Discute-se a forma como estas incompatibilidades são identificadas e apresentam-se estratégias e ferramentas para a sua solução, com ênfase em sugestões a serem incorporadas aos projetos arquitetônicos.

Palavras-Chaves: Compatibilização de projetos, projeto de produção de alvenaria, incompatibilidades projetuais. 


\section{INTRODUÇÃO}

Nota-se uma crescente valorização do projeto de produção de alvenaria de vedação, e as empresas incorporadoras e construtoras, aos poucos, vão se conscientizando da importância deste projeto como fator para a racionalização do processo de produção e redução de ocorrências de manifestações patológicas (AQUINO, 2004). Sendo assim, torna-se importante a análise das dificuldades apresentadas ao longo do seu desenvolvimento projetual. Muitas dessas dificuldades são decorrentes de falhas na compatibilização dos projetos e, sobretudo, da contratação tardia dos projetos para a produção, quando as principais definições relativas a concepção arquitetônica, bem como outros parâmetros construtivos, já foram definidos. Sendo assim, uma análise de como essas incompatibilidades se manifestam e que mecanismos podem ser propostos para sua diminuição trará um impacto positivo na implementação dos projetos de produção nos canteiros de obras.

Com esse objetivo, o presente trabalho apresenta um estudo de caso realizado junto a dez empreendimentos que adotaram o projeto de produção de alvenaria. Esses empreendimentos são brevemente caracterizados, ressaltando o fato de que diferentes culturas organizacionais e processos construtivos devem ser considerados na execução dos projetos.

A partir das características específicas dos empreendimentos, os problemas mais freqüentes e que mais impactam o desenvolvimento do projeto de produção são identificados. Descrevem-se alguns mecanismos para solução desses problemas durante a atividade projetual, em particular os relativos ao projeto arquitetônico.

\section{OS ESTUDOS DE CASO}

\subsection{Caracterização geral dos empreendimentos}

Os estudos de caso são detalhadamente descritos na dissertação de mestrado de um dos autores (CORREA, 2006). Em todos os empreendimentos, brevemente caracterizados na seqüência, foram desenvolvidos os projetos para a produção de alvenaria de vedação. Foram estudados dez empreendimentos de oito empresas incorporadoras / construtoras, e uma breve descrição dos empreendimentos, quanto ao porte e tipo, é mostrada na Tabela 1.

A tabela 1 mostra que a maior parte dos empreendimentos refere-se a edificações habitacionais de alto padrão. De fato, no mercado de Belo Horizonte ainda persiste, nesse segmento, a utilização de vedação em blocos cerâmicos. Em outros segmentos, como edificações comerciais, nota-se uma progressiva substituição da vedação convencional pelo gesso acartonado, sobretudo em alvenarias internas, que neste caso não justifica a utilização de projetos para produção de alvenaria.

A amostra de empresas representada na tabela acima sugere que a contratação do projeto de alvenaria ocorre na maioria das vezes em empreendimentos e em empresas de maior porte. Este fato é justificado pelas seguintes razões: 
Tabela 1: Carcterização geral dos empreendimentos

\begin{tabular}{|c|c|c|c|c|c|c|c|c|}
\hline EMPRESA & $\begin{array}{l}\text { POSIÇÃO } \\
\text { MERCADO }\end{array}$ & EMPREENDIMENTO & TIPO & $\begin{array}{c}\text { No. } \\
\text { UNIDADES }\end{array}$ & $\begin{array}{l}\text { No. } \\
\text { PAV. }\end{array}$ & $\begin{array}{c}\text { PADRÃO } \\
\text { LUXO }\end{array}$ & LOCALIDADE & $\begin{array}{c}\text { No. EMPREEND. } \\
\text { EXECUTADOS } \\
\text { ANTERIORMENTE } \\
\text { C/ ALV. RACIONALIZADA. }\end{array}$ \\
\hline \multirow{2}{*}{ A } & \multirow{2}{*}{ GRANDE PORTE } & $\mathrm{A} 1$ & RES. & 28 & 17 & ALTO & $\mathrm{BH}$ & 0 \\
\hline & & $\mathrm{A} 2$ & RES. & 14 & 8 & ALTO & $\mathrm{BH}$ & 3 \\
\hline $\mathrm{B}$ & GRANDE PORTE & B1 & RES. & 24 & 15 & ALTO & $\mathrm{BH}$ & 0 \\
\hline $\mathrm{C}$ & MÉDIO PORTE & $\mathrm{C} 1$ & RES. & 52 & 16 & MÉDIO & $\mathrm{BH}$ & 1 \\
\hline $\mathrm{D}$ & MÉDIO PORTE & D1 & RES. & 52 & 14 & MÉDIO & $\mathrm{BH}$ & 0 \\
\hline $\mathrm{E}$ & MÉDIO PORTE & E1 & сом. & 116 & 10 & ALTO & $\mathrm{BH}$ & 0 \\
\hline \multirow[t]{2}{*}{$\mathrm{F}$} & \multirow{2}{*}{ GRANDE PORTE } & $\mathrm{F} 1$ & RES. & 46 & 23 & ALTO & $\mathrm{BH}$ & 9 \\
\hline & & $\mathrm{F} 2$ & RES. & 40 & 13 & MÉDIO & $\mathrm{BH}$ & 8 \\
\hline G & PEQUENO PORTE & G1 & RES. & 8 & 8 & MÉDIO & $\mathrm{BH}$ & 0 \\
\hline $\mathrm{H}$ & GRANDE PORTE & $\mathrm{H} 1$ & RES. & 288 & 24 & ALTO & RJ & 0 \\
\hline
\end{tabular}

- Otimização da implementação do projeto para produção em empreendimentos com o maior número de pavimentos-tipo, conseguindo-se uma maior racionalização na execução e no tempo despendido (maiores taxas de produtividade) à medida que a alvenaria é repetida em um número maior de pavimentos;.

- Tendência maior de contratação dos projetos para produção por empresas de maior porte, cujo volume de obras induz a adoção de ações de padronização de soluções e métodos executivos em função dos custos elevados dos insumos. Qualquer economia torna-se um atrativo para as empresas construtoras;

- Estas empresas têm acesso mais fácil às tecnologias e métodos mais inovadores, porque são, gerencialmente, mais articuladas, possuem departamentos técnicos estruturados com pessoal mais qualificado;

- As empresas de maior porte se baseiam no benchmarking, ou seja, elas norteiam-se por informações sobre o que seus concorrentes estão praticando no mercado, uma vez que fornecem para o mesmo mercado - alvo;

- O perfil estratégico das empresas de maior porte é mais prospectivo.

Os estudos de caso envolveram: (i) a análise da "cultura construtiva" e da tecnologia construtiva empregada pelas empresas, a partir de um questionário preenchido pelos empreendedores antes do início dos projetos, entrevistas e visitas a outras obras das empresas; (ii) desenvolvimento do projeto para a produção, de acordo com o escopo apresentado em Corrêa (2006); (iii) reuniões para compatibilização dos projetos para a produção com os projetos arquitetônicos e complementares; (iv) treinamento dos operários e encarregados nos canteiros de obra; (v) acompanhamento da execução e (vi) avaliação dos resultados da utilização desses projetos, por meio de questionários, observações in loco e registros fotográficos.

\subsection{Inserção do projeto para a produção da alvenaria no processo de projeto}

É importante ressaltar que, com exceção de um dos empreendimentos, em todos os demais os projetos para a produção de alvenaria foram contratados uma vez que os projetos arquitetônicos e complementares já haviam sido desenvolvidos, e em 
poucos casos houve a possibilidade de serem propostas alterações conceituais, visando a racionalização da execução da alvenaria.

Conforme afirmam Medeiros e Franco (1999), a elaboração adequada de um projeto específico voltado à produção das alvenarias é o ponto mais importante para o sucesso da execução. O projeto de alvenaria deve antecipar as decisões necessárias à execução das paredes, verificando e equacionando suas interferências com outras partes da obra e definindo o processo de produção e a qualidade do produto final.

O projeto para produção, quando elaborado somente por ocasião do desenvolvimento do projeto executivo, na maioria dos casos não tem o mesmo potencial de racionalização que teria se tivesse sido iniciado na fase de anteprojeto, o que seria mais desejável (Aquino, 2004).

Dentro deste contexto projetual, no qual os projetos para produção são desenvolvidos simultaneamente e não seqüencialmente aos outros projetos, conforme Barros (1996), as interferências entre os diversos subsistemas, tais como modulação, passagens de instalações, posicionamento de shafts e outros detalhes poderão ser identificados e, portanto, minimizadas.

Apesar destes conceitos serem consensuais nos meios acadêmicos, a literatura recente mostra uma tendência de contratação dos projetos para produção de alvenaria somente após a compatibilização dos anteprojetos, quando da realização dos projetos executivos (Barros e Sabatini, 2003). Segundo os autores, no processo de desenvolvimento de projeto, a partir de uma pesquisa realizada com cerca de vinte construtoras, os projetos para produção são iniciados somente após a compatibilização dos anteprojetos, quando da realização dos projetos executivos. Neste caso, Barros (1996) confirma a redução do potencial de racionalização. Isso porque, neste momento, se perde a oportunidade de compatibilizar alguns itens relevantes como: os vãos da estrutura com a modulação da alvenaria, com conseqüente corte de blocos, a modulação da alvenaria com as aberturas para as esquadrias de portas e janelas e o posicionamento das instalações com as características da alvenaria, inviabilizando, ma maioria dos casos, a inserção de shafts ou mesmo a passagem dos eletrodutos pelos componentes. Referenciando este mesmo trabalho da autora, vale ressaltar que, apesar de um menor potencial de racionalização, é desejável a contratação do projeto de alvenaria de vedação, pois o seu desenvolvimento permitirá a identificação e definição de alguns detalhes importantes como: identificação dos blocos a serem cortados para ajuste à modulação, ligação alvenaria-estrutura, relação alvenaria-esquadria com seus elementos estruturais e alvenaria-instalação, definição de detalhes construtivos e especificações de materiais, componentes e técnicas construtivas.

Uma prática normal entre as empresas é a contratação dos projetos arquitetônicos logo na efetivação do empreendimento. As demais contratações, inclusive os projetos para produção, deveriam ocorrer simultaneamente, o que não é comum. Quando é possível esta contratação "quase" simultânea de todos os projetos, esta ação permitirá que as definições e decisões de projeto sejam tomadas em conjunto, de forma harmônica e integrada.

Mesmo quando o projeto para a produção é contratado "tardiamente", através da aplicação de um questionário de reconhecimento da empresa, cuja metodologia é citada nas referências (Correa, 2006), é realizado o levantamento de dados a 
respeito da documentação referente aos diversos segmentos projetuais existentes (projetos estrutural, instalações, arquitetônico, executivos, detalhamentos, especificações, etc) relativos aos empreendimentos da empresas participantes. A existência de projetos complementares é por si só um fator determinante na contratação dos projetos para produção, ou seja, ao levantar os projetos já elaborados, já se tem em mente que o potencial de racionalização do projeto para produção de alvenaria poderá ficar comprometido, já que os "problemas relativos à vedação têm sido minimizados em virtude de uma melhor discussão durante a coordenação" (Aquino, 2004), no início do desenvolvimento dos trabalhos. Ou seja, a intervenção do projetista fica restrita somente ao levantamento de interferências evidenciadas no processo de compatibilização, reduzindo a possibilidade de inserção de novos parâmetros conceituais e racionalizadores que se são agregados aos projetos para produção.

Nos empreendimentos A1, A2, B1, C1, D1, F1 e F2, os projetos arquitetônicos e complementares já haviam sido elaborados e as obras já iniciadas e o fato da contratação ter ocorrido neste momento tornou o processo de produção de alvenaria mais "engessado", não tendo o mesmo potencial de racionalização que teria se tivesse sido iniciado na fase de anteprojeto como ocorreu na empresa G1, fato este que não permitiu a introdução de parâmetros projetuais como a racionalização de cortes nestes empreendimentos. Na empresa G1, houve a possibilidade de análise crítica dos estudos preliminares e discussão de determinados parâmetros racionalizadores com os demais projetistas, possibilitando a sua inserção nesta etapa inicial, como a introdução de shafts, adequação de vãos ao sistema "porta-pronta" junto à circulação do apartamento, ajustes dimensionais possíveis para obtenção de melhor distribuição modular, entre outros.

Nos empreendimentos E1 e H1, o processo apresentou um caráter um pouco mais flexível, pois a inserção dos projetos para produção aconteceu numa etapa em que alguns projetos estavam em desenvolvimento e outros já tinham sido entregues.

Em relação aos empreendimentos C1, D1 e E1, a contratação de projeto para produção de alvenaria pelas empresas foi um fato inédito na sua cultura. Configurou-se assim uma situação na qual o projetista trava uma "batalha" para superar os paradigmas culturais existentes, que se expressam inicialmente na falta de crédito ao serviço oferecido (projeto para a produção) ou no próprio desconhecimento do processo. Assim, o primeiro obstáculo a ser vencido é o de convencer os profissionais envolvidos da importância e eficácia desses projetos. Nas empresas estudadas, isso foi feito pela demonstração das experiências já vivenciadas em outras empresas, mostrando-se registros fotográficos de obras com a alvenaria racionalizada, projetos já elaborados e resultados obtidos em vários canteiros. Só então ocorreu a contratação dos projetos.

Nos empreendimentos F1 e F2, a contratação ocorreu após a elaboração do projeto executivo "compatibilizado" de arquitetura pela empresa, que, na realidade, é resultado da sobreposição dos projetos complementares com o projeto arquitetônico. Ainda que, em um primeiro momento, a contratação do projeto para a produção de alvenaria realizado após a elaboração do projeto compatibilizado, chamado "executivo" pela empresa contratante, possa parecer um fator minimizador de potenciais interferências, na prática não foi o que aconteceu. Ao 
contrário, o número de interferências e pendências foi significativo, sobretudo em relação à divergências entre este projeto dito " compatibilizado" e os demais, constatando-se a falta de comunicação aos diversos projetistas das alterações realizadas durante elaboração desta compatibilização.

Na empresa B1, o desenvolvimento do projeto para a produção da alvenaria foi realizado após a concretagem da primeira laje, fato relativamente comum. Isto ocorre com freqüência em função da própria cultura da empresa que considera o projeto de alvenaria como um simples projeto de paginação, e não como um processo mais sistêmico que envolve não só a execução da alvenaria, mas, também, toda a preparação relativa a serviços preliminares, como é o caso da marcação de eletrodutos em lajes, etapa esta fundamental para a correta marcação posterior da alvenaria.

Fatos como esses parecem indicar que o construtor baseia-se no paradigma de que o projeto para a produção estaria associado exclusivamente ao momento de execução da alvenaria, desconsiderando que tal projeto tem grande influência sobre outras etapas da construção. Ao pensar assim, a referência temporal para a contratação do projeto passa a ser o cronograma de obras. Desta forma, não se torna possível incorporar, na etapa do desenvolvimento do produto edificação, conceitos que aumentem o potencial de racionalização construtiva, como mencionado anteriormente.

Um exemplo comum, observado nos estudos de caso, decorrente dessa contratação tardia do projeto para a produção, é a marcação dos eletrodutos das lajes já concretadas, que será incompatível com a marcação da alvenaria em relação à locação dos pontos elétricos de subida/descida, fato este que evitaria os cortes posteriores na alvenaria. Isso gera uma série de dificuldades no embutimento dos eletrodutos dentro das alvenarias, provocando quebra e entulho dos blocos cerâmicos.

A contratação tardia reduz significativamente o potencial de aplicação efetiva dos conceitos de Engenharia Simultânea em relação à cooperação e ao consenso entre os envolvidos no desenvolvimento, uma vez que não se adotou o conceito de projeto simultâneo, fundamentado na orientação simultânea e conjunta entre os vários profissionais, na organização de forma adequada do fluxo de informação entre eles e na condução das decisões a serem tomadas na fase inicial de concepção do empreendimento. A constituição de equipes multidisciplinares de projeto, desde suas primeiras fases, cuja principal responsabilidade estabelece altos níveis de integração e comunicação, com procedimentos de coordenação de projeto metodologicamente estabelecidos, ao invés de isolar as disciplinas ou especialidades com a adoção da forma seqüencial e não iterativa de elaboração do projeto, constitui um fator relevante dentro dos pressupostos da Engenharia Simultânea.

Por outro lado, a qualidade final do projeto reflete não só a competência específica de cada projetista, mas principalmente, a interação facilitada pelo nível de relacionamento entre eles.

Em função da contratação tardia, a integração do projetista de produção com os demais projetistas ficou comprometida e o fluxo de informações foi deficiente, uma vez que as reuniões de coordenação já aconteceram. Nos empreendimentos 
A1, A2, B1, F1 e F2 em que a contratação dos projetos para produção ocorreu após a elaboração de todos os projetos, observou-se certa resistência, entre projetistas das demais especialidades, em retomar um projeto, para eles, já concluído e entregue. Salientam que é demandado um tempo até que eles possam se inteirar novamente daquele projeto.

Nos empreendimentos E1 e H1, o processo foi mais dinâmico, pois na medida em que os projetos iam sendo emitidos, mesmo em versões preliminares, foi possível, neste momento, realizar uma análise prévia das soluções adotadas e as interferências eram enviadas imediatamente ao projetista em espaços de tempo relativamente curtos. Este "dinamismo" esboçou, nestes empreendimentos, um processo simultâneo de elaboração de projetos.

Em momentos iniciais de discussão de concepção do projeto, como aconteceu no empreendimento G1, esta integração entre projetistas dos diversos segmentos projetuais foi constatada através da realização de reuniões preliminares para troca simultânea de informações.

\subsection{Mecanismos de coordenação de projetos}

Com exceção dos empreendimentos B1 e G1, observou-se a presença de um coordenador de projetos, ainda que, na maioria dos casos, essa atividade de coordenação não ocorreu de maneira sistêmica, seguindo um procedimento gerencial previamente definido.

Verificou-se que nas empresas onde a coordenação de projetos é um mecanismo presente, tendo à frente profissionais capacitados para esta função, ou seja, nas empresas referentes aos empreendimentos $\mathrm{C} 1, \mathrm{~F} 1, \mathrm{H} 1$, o tempo para repasse de informações foi reduzido, uma vez que as solicitações feitas pelo projetista através de relatórios de compatibilização, são, na maioria das vezes, atendidas pelo coordenador em um tempo hábil. Nas empresas B1, G1, onde não há absolutamente nenhum mecanismo de coordenação, o projetista torna-se um "coordenador temporário", uma vez que cabe a ele buscar as informações necessárias e resolver incompatibilidades projetuais junto aos outros profissionais para o desenvolvimento de seus trabalhos.

\subsection{Parâmetros arquitetônicos e sua influência nos projetos para a produção}

Através dos parâmetros da Tabela 2 é possível analisar as características arquitetônicas dos empreendimentos que mais impactam os projetos de alvenaria quanto à sua racionalização.

Verifica-se que nenhum empreendimento utilizou a ferramenta de modulação de projeto, que elimina cortes posteriores e ajustes dimensionais. Desta forma, foi necessária a utilização, em todos os projetos, de subcomponentes modulares para compensação de medidas. Esta medida reduz o potencial de racionalização do produto final, indo de encontro aos pressupostos do Design for Manufacturing, cujas ferramentas são aquelas que racionalizam o processo, recursos e o produto final. 
Tabela 2: Caracterização dos empreendimentos quanto às soluções arquitetônicas utilizadas

\begin{tabular}{|c|c|c|c|c|c|c|c|c|c|}
\hline $\begin{array}{c}\text { SOLUÇÃO } \\
\text { ARQ. }\end{array}$ & $\begin{array}{c}\text { No.UNID. } \\
\text { POR PAV. }\end{array}$ & $\begin{array}{c}\text { No. } \\
\text { TIPOLOGIAS }\end{array}$ & $\begin{array}{c}\text { UTILIZAÇÃO } \\
\text { MECANISMO } \\
\text { MODULAÇÃO }\end{array}$ & $\begin{array}{c}\text { No. ESP. } \\
\text { ALVENARIAS } \\
\text { UTILIZADAS }\end{array}$ & $\begin{array}{c}\text { PAREDE } \\
\text { CURVA }\end{array}$ & $\begin{array}{c}\text { ADEQUAÇÃO } \\
\text { A ESTRUTURA }\end{array}$ & $\begin{array}{c}\text { No. } \\
\text { VARIAÇÕES } \\
\text { TIPO }\end{array}$ & $\begin{array}{c}\text { No. } \\
\text { REPETIÇÕES } \\
\text { TIPO }\end{array}$ & $\begin{array}{c}\text { PÉ } \\
\text { DIREITO } \\
\text { (CM) }\end{array}$ \\
\hline A1 & 2 & 1 & AUSENTE & 3 & AUSENTE & NÃO & 0 & 14 & 280 \\
\hline A2 & 2 & 1 & AUSENTE & 4 & AUSENTE & NÃO & 0 & 7 & 268 \\
\hline B1 & 2 & 1 & AUSENTE & 3 & PRESENTE & NÃO & 0 & 12 & 263 \\
\hline C1 & 4 & 1 & AUSENTE & 2 & PRESENTE & SIM & 0 & 13 & 296 \\
\hline D1 & 4 & 1 & AUSENTE & 2 & AUSENTE & SIM & 0 & 13 & 267 \\
\hline E1 & 16 & 10 & AUSENTE & 3 & PRESENTE & SIM & 4 & 6 & $310 / 320$ \\
\hline F1 & 2 & 1 & AUSENTE & 2 & PRESENTE & SIM & 0 & 23 & $276 / 286$ \\
\hline F2 & 4 & 1 & AUSENTE & 2 & AUSENTE & SIM & 0 & 20 & $286 / 271$ \\
\hline G1 & 1 & 1 & AUSENTE & 3 & PRESENTE & NÃO & 0 & 8 & $276 / 278$ \\
\hline H1 & 12 & 5 & AUSENTE & 2 & AUSENTE & SIM & 0 & 36 & 264 \\
\hline
\end{tabular}

Quanto ao número de apartamentos por andar, quanto maior a repetição de tipologias no mesmo pavimento, maior o potencial de racionalização. De acordo com a Tabela 2, somente os empreendimentos C1, D1 e F2 apresentam maior repetição com quatro apartamentos de mesma tipologia no pavimento. $O$ empreendimento $\mathrm{H} 1$ tem seu potencial de racionalização reduzido em função do grande número de tipologias diferenciadas por pavimento; entretanto apresenta um número alto de repetições do pavimento tipo, o que melhora o seu ranking racionalizador.

Os empreendimentos A1, A2, B1 e F1, caracterizados por dois apartamentos por andar com uma mesma tipologia, apresentam um potencial racionalizador menor que a solução de quatro tipologias que se repetem num mesmo pavimento (maior potencial) e maior do que a solução de uma só tipologia (menor potencial, um apartamento por andar).

Os empreendimentos E1 e G1 apresentam o menor potencial de racionalização. O primeiro em função da repetição tanto de tipologias e variação do pavimento tipo e o segundo, em função de ser um apartamento por andar.

Essa caracterização aponta para o fato de que parâmetros arquitetônicos, em especial a definição do número de tipologias e apartamentos nos pavimentos-tipo, são características de grande impacto na concepção dos empreendimentos no sentido de possibilitarem ou não a adoção posterior do DFMA nos projetos de produção, cujos princípios estão focados na identificação, durante a fase concepção do produto, dos meios para se obter uma "fabricação" do produto de forma mais fácil. Isto permite assegurar, de maneira eficaz, a união das necessidades e os requerimentos do produto, simplificar e aperfeiçoar a fabricação dos componentes que formarão o produto depois de montado.

No entanto, em nenhum dos empreendimentos este aspecto não foi levado em conta no momento da definição dos programas de necessidades do empreendimento.

O elevado número de espessuras de alvenarias é um fator que tem também influência o potencial racionalizador do empreendimento, pois reduz a possibilidade de padronização. Verifica-se que o empreendimento A2 obteve maior número de espessuras de alvenaria, o que impacta o projeto de alvenaria em relação às amarrações, pois, quanto maior o número de espessuras de blocos, maior 
é a dificuldade de amarração entre eles. A presença de juntas grampeadas ou a prumo, caracterizadas por juntas solidarizadas através de ferros ou telas, se faz necessária.

Outro fator que reduz a racionalização do processo é a presença de paredes curvas, cuja execução é mais "artesanal" do que a parede convencional, pois envolve maior habilidade do operário na execução, em função da utilização de subcomponentes modulares com amarrações mais complicadas. Constatou-se que os empreendimentos B1, C1, E1 e F1 apresentaram esta solução. Também a multiplicidade de alturas de pé-direito presente nos empreendimentos E1, F1, F2, e G1 é um fator que influencia o potencial de racionalização, cuja variação induz a soluções diferenciadas e não padronizadas de modulação vertical e conseqüente aumento de compensadores de medidas.

O quesito de adequação à estrutura, caracterizado pela compatibilidade da estrutura em relação à solução arquitetônica, evidenciou, através da Tabela 2, que ainda há empreendimentos com esta falha de compatibilidade, exemplificado pelos empreendimentos A1, A2, B1 e G1, e que foi detectada pelo projetista de alvenaria através da sobreposição dos desenhos. Esta falha é evidenciada, sobretudo, quando da inserção do posicionamento de pilares e vigas no projeto de arquitetura.

Em outro trabalho, Corrêa,Andery (2005) ressaltam que, para que se aproveite todo o potencial dos projetos para a produção de alvenaria, torna-se importante que se tenha um diagnóstico sobre a cultura tecnológica construtiva assim como os processos e procedimentos utilizados pelas construtoras. De acordo com a metodologia desenvolvida, este diagnóstico é viabilizado pela aplicação de questionários e check-lists. Isso permite um cuidadoso levantamento de dados a respeito dos procedimentos construtivos das empresas, que serão levados em conta no desenvolvimento do projeto para a produção. Em todas as empresas, no ato da contratação do projeto de produção de alvenaria, foi realizado, como mencionado acima, este levantamento das características construtivas próprias de cada empresa. Esse levantamento abrangeu aspectos como: especificações e espessuras de piso e para levantamento de interferência no nível dos vãos de portas, utilização ou não do sistema porta-pronta para definição dos vãos, utilização do sistema laje nível zero (necessário ao levantamento de interferência na paginação vertical e na determinação das juntas de regularização), utilização ou não de pré-moldados em vergas, contravergas e shafts e a especificação de revestimento das fachadas, para levantamento de interferência na definição de vãos de esquadrias, entre outros aspectos.

Esses procedimentos mostraram-se fundamentais na identificação de deficiências conceituais entre o que se propõe no projeto arquitetônico e o que se executa em obra, atuando como mecanismo auxiliar para minimização desses problemas no desenvolvimento do projeto de produção de alvenaria.

\subsection{Levantamento das interfaces com os diversos subsistemas e a tarefa de compatibilização dos projetos}

Andery; Vanni; Borges (2000) destacam que, com muita freqüência, os projetos chegam à obra incompletos, necessitando de informações adicionais durante as obras, o que freqüentemente acarreta em "improvisações". Além disso, segundo 
estes autores, muitas vezes os projetos não são claros e, em diversos casos, são verificadas incompatibilidades entre as especialidades de projeto, prejudicando o andamento da obra e a qualidade do produto. Assim, um mecanismo de compatibilização favorece a eliminação de incertezas nos projetos, de retrabalhos e da necessidade de desenvolvimento de soluções durante a obra, o que amplia a racionalidade e construtibilidade dos projetos, dentro dos pressupostos da Engenharia Simultânea.

No universo de subsistemas de uma obra, a alvenaria é talvez aquele que mais sofre interferência dos demais, o que a torna um agente com capacidade de alavancar benefícios, já que as ações sobre esta atividade necessariamente resultam em modificações nos demais.

Em função deste cenário, é que são discutidas as incompatibilidades, eventuais deficiências e pontos críticos dos subsistemas prediais, que apresentam interface com a alvenaria de vedação. A análise prévia das interfaces presentes entre as alvenarias e os demais subsistemas da obra (estrutura, revestimentos, instalações e esquadrias) objetiva minimizar a tomada de decisões no canteiro, possibilitando um planejamento da produção com níveis altos de confiabilidade tanto para o estabelecimento de prazos, quanto para a quantificação de insumos.

Assim, o projetista de alvenaria incorpora um caráter, no seu perfil profissional, de um integrador de soluções, pois, através da realização desta análise crítica, técnica e conceitual, o trabalho de compatibilização envolve não só o levantamento das interferências e deficiências, mas também promove a interface com os diversos participantes, através das discussões geradas a partir das questões levantadas. Esta participação conjunta e troca de informações está em sintonia com um dos princípios da Engenharia Simultânea relativo à interação da equipe para obtenção de soluções multidisciplinares conjuntas. $\mathrm{Na}$ realidade, este processo de compatibilização, realizado pelo projetista de produção, agrega alguns objetivos de coordenação de projetos, segundo Melhado et al (2005), como fomentar a interatividade na equipe de projeto na busca pela qualidade dos projetos assim desenvolvidos, através de discussões de diferentes profissionais para se atingir a uma solução ótima.

A compatibilização, elaborada nos dez empreendimentos, foi realizada utilizando os recursos da informática, através da sobreposição de desenhos realizada no software AUTOCAD. Esta ferramenta permite evidenciar potenciais interferências, e que, segundo Romeiro (1993), constitui forma desenvolvida de interação do computador digital à atividade de projeto, bem como ao controle da gestão deste processo, onde o desenvolvimento dos projetos processa-se de forma ordenada e correlacionada.

Em todos os empreendimentos estudados, os projetos não apresentaram nenhuma padronização de representação gráfica entre si, com uma enorme diversidade de layers, escalas e ambientes computacionais diferenciados, o que dificultou de certa maneira a agilidade do processo de levantamento de interferências, tendo em vista a necessidade de ajustes necessários.

Desta forma, a padronização quanto à apresentação dos desenhos mostrou ser um fator de grande importância para conferir a esta etapa maior confiabilidade e rapidez, "uniformizando-se entre os projetistas desde a escolha do software até a 
configuração básica das ferramentas de auxílio ao desenho, tais como padronização de layers, estilos de textos, sistemas de cotas, criação e inserção de blocos para componentes, dentre outros" (Silva, 2003).

Nos empreendimentos estudados, as questões levantadas foram formalizadas através de relatórios elaborados para cada subsistema projetual, onde foram registradas as interferências e encaminhadas aos projetistas e/ou coordenadores de projetos para imediata solução.

De uma maneira geral, as interfaces mais comuns relacionadas aos principais conceitos projetuais e levantadas no processo de desenvolvimento de projetos para produção de alvenaria nos dez empreendimentos estão relacionadas com:

- Interferências e inconsistências geométricas entre projetos do produto evidenciadas pela atividade de compatibilização, por exemplo, diferenças de cotas entre projeto de arquitetura e estrutural; divergências de localização de equipamentos, tais como máquina de lavar, tanque, fogão, entre outros;

- Inconsistências relacionadas ao desempenho e à execução dos sistemas e entre os subsistemas, impactando na construtibilidade, por exemplo, a falta de definição de subsistemas a serem incorporados na fase inicial de elaboração e definição somente durante o desenvolvimento de projeto (ex: porta pronta);

- Inconsistências relacionadas ao controle da comunicação, do tempo, do escopo, de custos, riscos e integração por parte da coordenação, por exemplo, a falta de controle de revisões de projeto, a contratação tardia do projeto para produção no momento da concretagem das lajes e a falta de comunicação de alterações realizadas na obra;

- Omissões, contradições ou inexistência de informações e especificações relacionadas ao produto, como a indefinição quanto a acabamentos;

- Ineficiências do método de trabalho para produção, por exemplo, o conflito entre o método proposto e o método executado e alterações freqüentes do projeto pela obra.

A título de exemplo, a figura 1 ilustra algumas interferências levantadas pelo projetista de alvenaria no empreendimento $\mathrm{C} 1$, durante a compatibilização dos projetos.

Pela análise da figura, podem ser observadas diversas incompatibilidades, tais como:

- Divergência na localização do tanque e máquina de lavar roupa entre o projeto hidrosanitário e o arquitetônico;

- Tomada elétrica para máquina de lavar roupa descendo no pilar no projeto elétrico;

- Falta de indicação da estrutura nos projetos complementares (hidráulico e elétrico);

- Divergência na esquadria da cozinha entre os projetos hidráulicos/elétrico e o de arquitetura. 


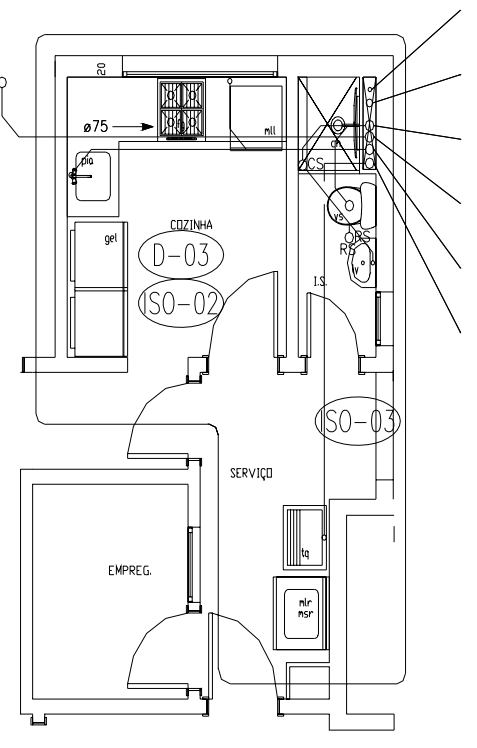

PROJETO HIDROSANITÁRIO

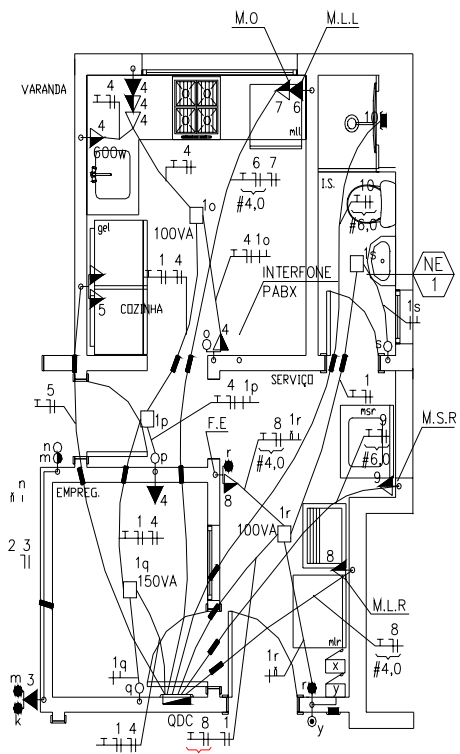

PROJETO ELÉTRICO

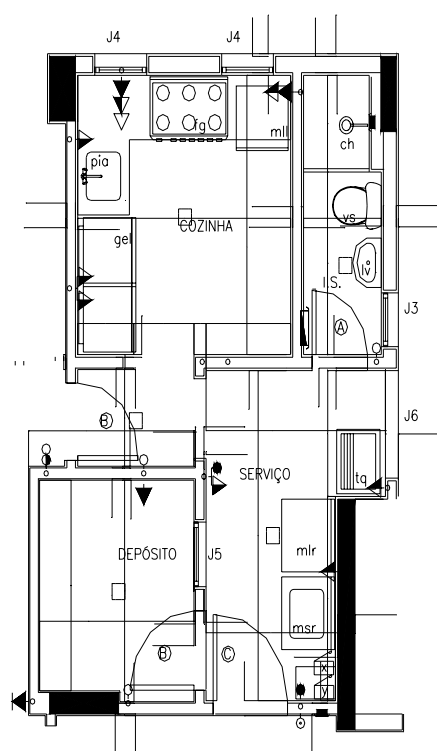

PROJETO ARQUITETÔNICO

Figura 1: Compatibilização entre projetos do empreendimento C1.

Os quadros 1 a 3 , a seguir, resumem os aspectos que mais se repetiram e impactaram na elaboração dos projetos para produção de alvenaria nestes empreendimentos, levando em conta potenciais interferências com os projetos arquitetônicos, de instalações elétricas e os projetos de estrutura. Também são identificadas ações corretivas e/ou preventivas para os diversos problemas identificados.

O quadro 1 mostra uma síntese das incompatibilidades mais comuns levantadas nos projetos de instalações nos empreendimentos estudados.

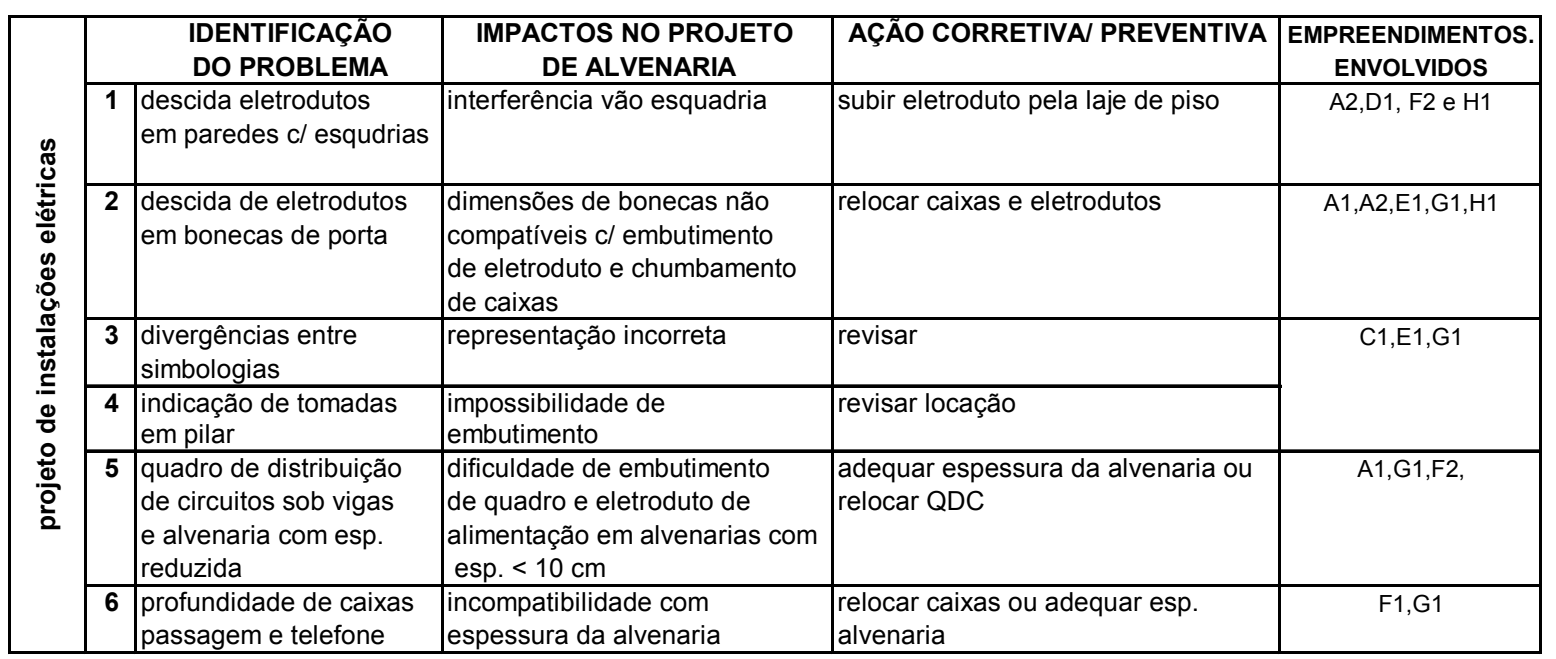

Quadro 1: Problemas mais freqüentes nos projetos de instalações elétricas dos empreendimentos

Na compatibilização com o projeto estrutural dos empreendimentos, a análise foi realizada levando-se em conta situações de paredes com solicitações específicas como, por exemplo: paredes sobre balanços, existência de juntas de trabalho e separação. As incompatibilidades levantadas foram encaminhadas aos interessados 
para as devidas providências e correções. Para Franco (1998), a análise do projeto estrutural, no qual irá se inserir a vedação vertical, é de fundamental importância para determinar tanto as características inerentes dos vedos que a compõe, como dos detalhes construtivos necessários ao bom desempenho desta, frente ao nível de solicitações esperadas.

O quadro 2 ilustra, entre empresas estudadas, as seguintes incompatibilidades nos projetos estruturais estudados:

\begin{tabular}{|c|c|c|c|c|c|}
\hline \multirow{3}{*}{ 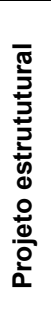 } & & $\begin{array}{l}\text { IDENTIFICAÇÃO } \\
\text { DO PROBLEMA }\end{array}$ & $\begin{array}{c}\text { IMPACTOS NO PROJETO } \\
\text { DE ALVENARIA }\end{array}$ & AÇÃO PREVENTIVA & $\begin{array}{c}\text { EMPREENDIMENTOS } \\
\text { ENVOLVIDOS }\end{array}$ \\
\hline & 1 & $\begin{array}{l}\text { falta de padronização } \\
\text { de vigas e lajes }\end{array}$ & \multirow{2}{*}{$\begin{array}{l}\text { racionalização ineficiente } \\
\text { aumento nos cortes } \\
\text { para acerto paginação vertical } \\
\text { aumento da variabilidade } \\
\text { de alvenarias }\end{array}$} & $\begin{array}{l}\text { estudar antecipadamente nas etapas } \\
\text { iniciais de projeto alturas e espessuras } \\
\text { de vigas e pé-direito com altura } \\
\text { modulada }\end{array}$ & $\mathrm{A} 1, \mathrm{~A} 2, \mathrm{~B} 1, \mathrm{~F} 1$ e G1 \\
\hline & 2 & $\begin{array}{l}\text { número significativo de } \\
\text { redução de pilar, } \\
\text { vigas invertidas e/ou } \\
\text { semi-invertidas, e lajes } \\
\text { rebaixadas }\end{array}$ & & \begin{tabular}{|l} 
modulada \\
estudar antecipadamente soluções \\
com equipe do projeto estrutural \\
nas etapas iniciais para eliminação
\end{tabular} & $\mathrm{A} 1, \mathrm{~B} 1$ \\
\hline
\end{tabular}

Quadro 2: Problemas mais freqüentes nos projetos estruturais dos empreendimentos

O quadro 3 mostra os problemas mais freqüentes identificados na compatibilização dos projetos executivos de arquitetura para adequação ao projeto de alvenaria.

\begin{tabular}{|c|c|c|c|c|}
\hline & $\begin{array}{l}\text { IDENTIFICAÇÃO } \\
\text { DO PROBLEMA }\end{array}$ & $\begin{array}{l}\text { IMPACTOS NO PROJETO } \\
\text { DE ALVENARIA }\end{array}$ & AÇÃO CORRETIVA PREVENTIVA & $\begin{array}{l}\text { EMPREENDIMENTOS. } \\
\text { ENVOLVIDOS }\end{array}$ \\
\hline & \begin{tabular}{l|l}
1 & $\begin{array}{l}\text { modificações } \\
\text { personalizadas nos } \\
\text { apartamentos }\end{array}$ \\
\end{tabular} & $\begin{array}{l}\text { aumento da variabilidade e falta } \\
\text { de padronização de alvenarias }\end{array}$ & $\begin{array}{l}\text { negociar modificações padronizadas } \\
\text { com clientes(ação preventiva) }\end{array}$ & $\mathrm{G} 1$ \\
\hline$\frac{\pi}{2}$ & 2 espalas em vigas e pilar & & $\begin{array}{l}\text { adequar a alvenaria à espessura } \\
\text { de viga e/ou pilar (ação corretiva) }\end{array}$ & $\mathrm{A} 1, \mathrm{~A} 2, \mathrm{~B} 1, \mathrm{G} 1, \mathrm{H} 1$ \\
\hline 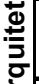 & \begin{tabular}{l|l}
3 & $\begin{array}{l}\text { variedade de esp. } \\
\text { de alvenarias }\end{array}$ \\
\end{tabular} & $\begin{array}{l}\text { necessidade de amarrações } \\
\text { em junto a prumo }\end{array}$ & \begin{tabular}{|l|} 
minimizar e padronizar \\
esp. alvenarias(ação preventiva)
\end{tabular} & $\mathrm{A} 1, \mathrm{~A} 2, \mathrm{~B} 1, \mathrm{E} 1 \mathrm{E}$ G1 \\
\hline . & \begin{tabular}{l|l}
4 & incompatibilidades entre \\
executivo e instalações
\end{tabular} & $\begin{array}{l}\text { qual o posicionamento correto } \\
\text { dos pontos? }\end{array}$ & $\begin{array}{l}\text { adequar a solução correta(ação } \\
\text { corretiva) } \\
\text { corrigir falhas de compatibilização } \\
\text { e coordenação (ação preventiva) } \\
\end{array}$ & $\begin{array}{c}\text { todos } \\
\text { os empreendimentos }\end{array}$ \\
\hline 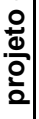 & 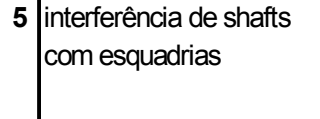 & redução do vão das esquadrias & $\begin{array}{l}\text { corrigir falhas de compatibilização } \\
\text { (ação preventiva) para levantamento } \\
\text { antecipado de interferências }\end{array}$ & $\mathrm{A} 2, \mathrm{D} 1, \mathrm{H} 1$ \\
\hline & $6 \begin{array}{l}\text { falta de indicação de } \\
\text { posicionamento } \\
\text { final de pilares }\end{array}$ & alteração de paginação & & $\mathrm{A} 1, \mathrm{~A} 2, \mathrm{~B} 1, \mathrm{D} 1, \mathrm{G} 1$ \\
\hline
\end{tabular}

\section{Quadro 3: Problemas mais freqüentes nos projetos arquitetônicos dos empreendimentos}

No quadro 3, as ações corretivas não foram apresentadas pelo fato do sistema estrutural já estar definido, não admitindo intervenções posteriores em todos os projetos contratados, e as ações preventivas somente são viáveis se aplicadas antecipadamente aos estudos iniciais de soluções estruturais.

A introdução de ações corretivas, como aquelas mostradas nos quadros acima, justifica-se em função da ocorrência da contratação tardia dos projetos para produção de alvenaria na maioria dos empreendimentos, e atuam como agentes 
minimizadores de eventuais interferências, fato este que poderia ser evitado nos momentos iniciais de concepção do projeto através de medidas preventivas e não corretivas.

Como pressuposto básico para a elaboração do projeto para produção de alvenaria de vedação tem-se a coordenação dimensional como uma série de procedimentos que objetivam a concordância das dimensões dos componentes ou subcomponentes. Para Franco (1998), a coordenação dimensional e modular "levaria a padronização dos detalhes construtivos, que além de facilitar a execução e controle dos mesmos, permitiria a padronização das soluções e o desenvolvimento de alternativas cada vez melhores para as diversas situações padrão".

Esta "modularidade ideal" é atingida quando este conceito é incorporado nas fases iniciais de concepção dos projetos, pois é neste momento que se elege uma unidade dimensional cujos múltiplos regulam as dimensões do projeto. Este procedimento consiste em reduzir a variedade dimensional, padronizando as dimensões possíveis e preferenciais, reunindo vantagens econômicas, técnicas e produtivas.

Este conceito de racionalização e coordenação dimensional é amplamente praticado na alvenaria estrutural, embora seja possível adotar os mesmos princípios na alvenaria de vedação. Entretanto esta prática não é comum em prédios estruturados, pois o projeto, neste caso, na maioria das vezes, não é concebido de uma forma integrada e simultânea desde os momentos iniciais de maneira que todos os intervenientes do processo trabalhem dentro das mesmas diretrizes de coordenação modular, fato este ocorrido em todos os empreendimentos estudados.

O conceito de coordenação modular na alvenaria de vedação é utilizado de uma forma fragmentada através da adoção "parcial" do conceito de utilização de componentes padronizados e coordenados dimensionalmente. Isto se deve em função da desvinculação do projeto arquitetônico e estrutural a um sistema coordenado, modular e padronizado de medidas. Em função desta realidade, foram introduzidos "procedimentos de ajustes de coordenação modular" nos empreendimentos estudados para a complementação dimensional dos vãos estruturais, cujas dimensões não apresentaram uma relação de proporcionalidade com um módulo padrão, por exemplo, o bloco cerâmico. Esta medida foi viabilizada pela criação de uma central de corte para a obtenção de submódulos geometricamente mais regulares, como aconteceu nos empreendimentos C1, D1, F1, F2 e G1.

Mesmo utilizando estes procedimentos "auto-ajustáveis" em todos os empreendimentos, em função de variáveis que limitam o potencial de racionalização como a própria configuração projetual e disponibilização de componentes no mercado junto ao fabricante, é possível aumentar este potencial. Isso é possível quando se consegue substituir o processo construtivo tradicional, em que o seccionamento de blocos cerâmicos é realizado com a colher de pedreiro, gerando mais entulho e consumindo mais argamassa, por um processo onde toda a produção é programada. Todo este conceito de programação da alvenaria foi incorporado aos projetos de alvenaria dos empreendimentos estudados através do levantamento de quantidades de material a ser utilizado em cada parede. 
Entretanto, uma verificação nos canteiros de obra demonstrou que alguns empreendimentos como A2 e G1 ainda operavam a forma artesanal de cortes.

As dificuldades levantadas, em sua maioria, são decorrentes de diretrizes não incorporadas nos projetos conceituais em função da contratação e participação tardias do projetista de alvenaria no processo de projeto do empreendimento.

Muitas vezes, o contratante "acredita" que está recebendo apenas uma paginação de alvenaria. Pode-se dizer o projeto para produção de alvenaria é fruto de um processo de compatibilização e análise das interfaces de todos os outros subsistemas projetuais. Trata-se de um "projeto para produção de um processo". Entretanto, os projetos de todos os empreendimentos apresentaram interfaces e incompatibilidades, que precisaram ser resolvidas, quando foi possível, ainda que na etapa de elaboração do projeto para produção.

Algumas dificuldades enfrentadas desde o momento da elaboração do projeto até a execução em obra, nos empreendimentos estudados, são indicadas a seguir.

\subsection{Dificuldades projetuais e executivas}

A seguir serão descritas as dificuldades mais comuns detectadas nos projetos dos empreendimentos estudados.

\section{Aspectos relativos à estrutura:}

A falta de padronização de alturas e espessuras de vigas e lajes gerou um grande número de situações de modularidade vertical, com grande incidência de cortes para compensação de alturas.

A utilização de vigas semi-invertidas também é um fator que dificulta a racionalização modular vertical. A figura 2 mostra um exemplo ocorrido nos empreendimentos A1 e A2 onde a solução de vigas semi-invertidas foi utilizada, e demonstram através da necessidade maior de utilização de submódulos cortados para compensação de altura na modulação vertical, a redução do potencial de racionalização quanto à modulação vertical.

Da mesma forma, a presença de rebaixos em lajes é uma situação desfavorável a continuidade da modulação vertical, sendo para isso necessário o corte de pequenos compensadores ou preenchimento e argamassa para nivelamento das fiadas. Isso é muito comum ocorrer em varandas e na transição para as áreas frias. Os empreendimentos que não adotaram a laje nivelada apresentaram esta solução (A1, A2, B1). 


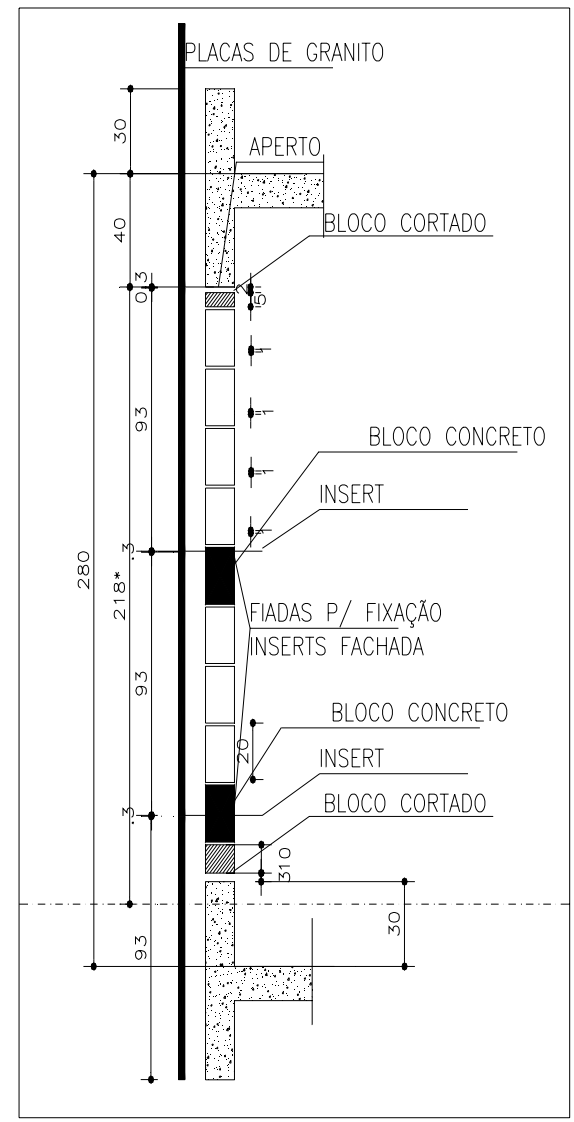

Figura 2: Situação de modularidade vertical com viga semi-invertida nos empreendimentos A1 e A2.

\section{Aspectos relativos às instalações}

No caso dos projetos de instalações, os quadros elétricos e de telecomunicações devem, preferencialmente, estar locados em paredes com espessura compatível com a sua respectiva profundidade, para evitar cortes posteriores na alvenaria para embutimento das tubulações.

O fato desta diretriz não ter sido assimilada no projeto de instalações leva muitas vezes a soluções "artesanais" de quebra e consumo de argamassa, o que foi observado em vários empreendimentos.

O esquecimento ou a marcação incorreta de alguns eletrodutos na laje em relação à indicação nos projetos de alvenaria acarreta uma série de inconvenientes como a quebra para embutimento de tubulações quando a alvenaria é levantada, gerando um grande volume desnecessário de entulho. Este fato ocorreu nos empreendimentos A1, E1 e H1, e pode ser observado com mais detalhe nas referências (Correa, 2006)

Esta geração de entulho se contrapõe a um dos pressupostos básicos preconizados do DFE (Design for Environment) que é prevenção da geração dos resíduos e emissões, através de uma íntima ligação entre projeto e desenvolvimento do produto, integrados ao meio ambiente. O projeto para produção de alvenaria propõe conceitos de racionalização de perdas pela redução de entulhos e pela eliminação de quebras através de ações como embutimento de eletrodutos em 
blocos com furos verticais, pré-chumbamento de caixas elétricas, programação de cortes mecanizados, entre outras.

Outras dificuldades podem ser apontadas em função da ausência de compatibilização entre a estrutura e as instalações, ou seja, a falta de indicação da estrutura no projeto hidrosanitário, por exemplo, gera soluções conflitantes de tubulações com descida em viga.

Os impactos são observados tanto na estrutura quanto na alvenaria, que por conseqüência, deverá ser quebrada para passagem destas tubulações.

\section{Aspectos relativos ao projeto arquitetônico}

A falta de padronização arquitetônica com a variação do pavimento tipo no empreendimento E1 implicou em uma complexidade projetual e executiva em função do aumento do número de alvenarias diferenciadas em cada pavimento. Da mesma forma, esta falta de padronização também foi percebida nas espessuras das alvenarias utilizadas, ocasionando, nos empreendimentos A1, A2, B1, E1e G1, problemas de amarrações entre paredes no projeto de alvenaria.

As alterações advindas de solicitações de clientes, que, na maioria das vezes, são vinculadas à aquisição do imóvel, impactam também o potencial de racionalização da alvenaria, fato este ocorrido no empreendimento B1. Gerenciar estas modificações específicas gera um retrabalho de tempo tanto para o projetista quanto para o executor, visto que, em geral, estas modificações podem ocorrer em momentos diferenciados na obra em que os serviços de alvenaria já foram concluídos. A quebra da alvenaria já concluída implica além do desperdício, retrabalho, geração de entulho e perda de produtividade.

A falta de indicação da estrutura nos projetos de arquitetura ocasionou interferências com instalações, dimensões de vãos de portas e janelas, presença de espalas dentro dos cômodos, entre outras, nos empreendimentos A1, A2, B1, D1 e G1, conforme mostra o Quadro 3 acima.

\section{DIRETRIZES CONCEITUAIS A SEREM INCORPORADAS AOS PROJETOS}

Com base nos estudo de caso, foram propostas diretrizes para incorporação, em etapas iniciais, aos diversos segmentos projetuais, tomando-se por base a análise das dificuldades encontradas nas soluções adotadas pelos projetos apresentados dos empreendimentos estudados.

A transferência de conhecimento e informação entre os diversos atores integrantes do desenvolvimento do produto-edificação torna-se um diferencial competitivo, partindo do princípio que a experiência acumulada na atividade de projetar poderá ser de grande importância. Isto porque, em um próximo projeto com características similares, certos cuidados serão tomados e certos erros, evitados. Ou seja, o knowhow adquirido, de forma a contribuir para a construção de uma base de dados visa à prevenção, ao controle de riscos, e, sobretudo, à aprendizagem coletiva. É a partir destas experiências coletadas que foram formatadas estas diretrizes propostas, a serem repassadas aos projetistas, em momentos iniciais de concepção do empreendimento, como elementos que irão agregar parâmetros projetuais, para o 
aumento do potencial de racionalização do processo de uma forma mais sistêmica e estabelecer de processo de comunicação formais mais interativos. A manutenção das equipes de projetos em outros empreendimentos, caracterizando uma relação de parceria projetista - empreendedor, permite que este know-how adquirido facilite a comunicação e a interação entre os projetistas.

Esta transferência de conhecimento através da proposição de diretrizes traduz ações de cooperação, confiança e compartilhamento, de forma que as decisões sejam tomadas, no início do processo, e constituem pressupostos básicos de um processo não seqüencial dentro da abordagem da Engenharia Simultânea.

Todas as diretrizes, a seguir, sugeridas para serem agregadas ao projeto arquitetônico, podem ser consideradas ferramentas de suporte para $o$ desenvolvimento dos outros projetos. Diretrizes relativas aos outros projetos são apresentadas nas referências (Correa, 2006). Ou seja, conforme preconizado pelo DFM , "projetar pensando-se na sua produção desde o primeiro momento (rightfirst-time for production), para que problemas potenciais de produção causados pelo projeto sejam solucionados ainda nas primeiras fases do projeto e não durante a produção" (Melhado et al, 1995), através da inclusão de considerações de "manufatura" ou produção no projeto para que haja comunicação entre todos os componentes de um "sistema de manufatura". Outro objetivo destas diretrizes é a simplificação do projeto e a padronização das partes que compõem o produto e o processo a ser utilizado, servindo de ponte de integração entre projeto e obra.

\section{Diretrizes para projeto arquitetônico}

Vale ressaltar que o objetivo da inserção destas diretrizes no momento de concepção do empreendimento deve estar em sintonia com a concepção arquitetônica adotada, ou seja, é desejável que estes conceitos racionalizadores dos projetos para produção de alvenaria possam ser assimilados sem que a concepção arquitetônica fique prejudicada ou limitada em seus parâmetros projetuais. O que se pretende é que estes conceitos possam permear os métodos de projetação efetivamente aplicados pelos arquitetos durante o processo de elaboração dos projetos.

A contratação do projeto para produção de alvenaria em momentos iniciais do processo de projetação do empreendimento favorece, conforme mencnionadoacima, favorece a racionalização do projeto no sentido da minimização da utilização de subcomponentes modulares, ou seja, os compensadores de medidas altimétricas, através de um pré-estudo de alturas em pé-direito livre e sob vigas. Pela antecipação da contratação do projeto, algumas diretrizes projetuais também podem ser agregadas na etapa inicial de concepção, antes da aprovação do projeto arquitetônico.

Entre essas diretrizes destacam-se a pré-definição de alturas de pé-direito e dimensionamento de vigas para racionalização da modularidade vertical e viabilização de vãos para porta-pronta. Segundo Barros (1996), na maioria das vezes a decisão pelo emprego desta tecnologia não se realiza previamente, e os vãos não são compatibilizados e analisados com antecedência, muitas vezes sobrando "folgas" indesejáveis, o que caracteriza uma completa desvinculação com o processo de produção do edifício. 
Além do aspecto descrito em relação à possibilidade de padronização de alturas de vigas e espessuras de lajes para eliminação dos cortes em paginação vertical, outras ações racionalizadoras e parâmetros projetuais podem ser salientadas quando o projeto para produção de alvenaria é contratado nos momentos iniciais de concepção do projeto arquitetônico. Entre estas ações, destacam-se:

1 - Fornecer subsídios aos projetistas de arquitetura quanto às espessuras de alvenarias em função de vários fatores: fornecedor, disponibilidade dimensional existente no mercado. Em todos os empreendimentos esta ação foi implementada através do levantamento das espessuras de paredes utilizadas no projeto arquitetônico, e da adequação à disponibilidade de fornecimento dos fabricantes locais;

2 - Evitar espessuras diferentes de alvenaria com amarrações complexas quando é necessário o uso de juntas grampeadas (paredes à 45o, encontro de três paredes com espessuras diferenciadas e paredes curvas);

3 - Promover padronização do pavimento tipo, evitando-se variações que possam impactar a repetição das soluções construtivas em um número maior de pavimentos, fator essencial para o aumento do potencial de racionalização na execução e produtividade.

Nos empreendimentos estudados, não foi possível a implementação destas ações (2 e 3), uma vez que, em todos os casos, o projeto de arquitetura já estava definido e aprovado, o que limita a aplicação de conceitos racionalizadores nesta fase.

4 - Fornecer diretrizes para determinação de larguras de circulação interna no caso da existência de portas confinadas entre paredes para implementação do sistema de porta-pronta. Esta ação impacta diretamente as dimensões necessárias para a largura mínima de vãos de portas, sobretudo quando se utiliza o sistema de portapronta, uma vez que é necessário contabilizar, além do vão em osso, as bonecas laterais para fixação dos batentes (marcos). O vão mínimo "em osso" exigido para a utilização do sistema porta-pronta, tecnologia hoje bastante praticada entre as construtoras, torna-se incompatível em relação às larguras de circulações apresentadas nos projetos arquitetônicos aprovados que atendem à dimensão mínima instituída pela legislação municipal. Este fato induz à soluções pouco racionais, como execução de bonecas em "massa" em função de suas dimensões reduzidas. Este fato tem seu impacto na instalação posterior dos chamados "alisares" das portas, que servem de arremate dos batentes. Essa foi a situação ocorrida no empreendimento B!, que em um primeiro momento descartou a possibilidade de adoção deste sistema, mas, reverteu esta decisão já em um momento adiantado do processo de execução da alvenaria, em que foram necessárias adaptações "emergenciais" no projeto para produção.

Nos empreendimentos que adotaram o sistema porta-pronta (A2, C1, D1, F1, F2, G1 e H1), a implementação do conceito de porta-pronta também exigiu ajustes para adequação dos vãos estabelecidos nos projetos de arquitetura, como redução de "bonecas".

5 - Fornecer orientação quanto à adoção de um sistema de coordenação modular, através da introdução de um módulo regulador para inserção do conceito de padronização ainda nas etapas iniciais de projeto. Este conceito, bastante praticado na alvenaria estrutural, tem um grande potencial de racionalização também ao ser 
aplicado nas alvenarias de vedação. Esta diretriz tem sua contribuição também efetiva na elaboração do projeto estrutural, pois contribui para a eliminação de cortes de peças de compensação de medidas ("espaçadores"). Não foi possível implementar esta ação nos empreendimentos estudados, tendo em vista, também, a aprovação já efetivada dos projetos arquitetônicos. Foi possível adotar um sistema modular "adaptado" às dimensões já pré-estabelecidas, que induziu o projetista a utilizar sub-componentes para compensação de medidas ("espaçadores") em todos os casos;

6 - Fornecer diretrizes quanto à compatibilidade dimensional para vãos de esquadrias (portas e janelas) de forma a eliminar complementos de componentes cortados para ajustes dimensionais, tanto na altura como na largura. A não implementação desta medida nos empreendimentos é justificada pelos mesmos fatores limitantes da ação anterior;

7 - Fornecer diretrizes, de forma coordenada com o projetista de instalações, para a previsão de shafts para hidrantes e instalações elétricas e telefônicas no hall dos apartamentos. Esta medida evita a quebra posterior da alvenaria para embutimento dos mesmos e passagens de tubulações de alimentação com diâmetros mais robustos. Trata-se de um parâmetro do DFA, baseado no principio da facilidade de montagem e manutenção.

Em todos os empreendimentos, o conceito de compartimentos "visitáveis" ou shafts foi incorporado desde os momentos iniciais de elaboração do projeto de arquitetura. Ou seja, todos os empreendimentos apresentaram esta solução. O que torna as soluções diferenciadas é a utilização de fechamento em pré-moldado (empreendimentos B1, C1, F1, F2, G1 e H1) ou alvenaria (empreendimentos A1, A2, D1 e E1). A utilização destes pré-moldados evita o corte posterior da alvenaria para acesso às tubulações.

8 - Propor "kits de modificações gerenciadas" em atendimento às expectativas do cliente quanto à realização de alterações com o intuito de promover padronização das soluções de modificação. Alterações "personalizadas", que na maioria das vezes são exigências contratuais para a efetivação da compra do imóvel, impactam, de forma negativa, o processo de execução da alvenaria. Entretanto, se estas variações forem gerenciadas previamente, através de um kit de modificação "padronizado" proposto ao cliente, é possível compatibilizar as suas exigências e necessidades com a gestão de produção nos canteiros. Desta forma, o projetista de alvenaria já poderia inserir estas modificações no momento de desenvolvimento dos trabalhos. Em nenhum dos empreendimentos foi possível implementar esta ação, por se tratar de uma ação estratégica a ser adotada pela empresa.

\section{CONCLUSÕES}

Fundamentada nas experiências extraídas da aplicação da metodologia proposta nos empreendimentos estudados, pode-se verificar que é possível aplicar os conceitos da Engenharia Simultânea, particularmente os orientados ao DFX, nos projetos para produção de alvenaria. É imprescindível que sejam observados determinados parâmetros, sobretudo em relação à simultaneidade das atividades, interatividade das equipes e gestão eficiente do processo de projeto. Nestas ações foram detectadas falhas em todos os empreendimentos estudados. Com efeito, 
pôde-se concluir que grande parte das falhas e incompatibilidades que reduziram o potencial de racionalização dos projetos para a produção foram decorrentes da contratação tardia desses projetos.

Mesmo nos casos em que o projetista atuou como um "compatibilizador" de projetos, sugerindo mudanças em parâmetros projetuais das outras disicplinas, dificuldades continuaram sendo observadas, dadas as dificuldades de mudanças nos projetos já desevolvidos.

Analisando estas falhas potenciais, percebe-se que é necessário, para a consolidação destes conceitos nas empresas, adotar medidas de cunho mais estratégico com a alteração da própria cultura técnico-organizacional, que é não é uma tarefa fácil.

Considerando este contexto vivenciado nas empresas, a principal contribuição que se pretende com a elaboração deste trabalho é viabilizar, através da introdução de processos e técnicas racionalizadas de execução de alvenaria, a redução de perdas de materiais e permitir que se estabeleça uma evolução do processo construtivo tradicional com a adoção dos pressupostos da Engenharia Simultânea.

Ao estabelecer o conjunto de diretrizes para inserção nos diversos segmentos projetuais, em suas etapas iniciais de concepção, propõe-se uma intervenção para a obtenção de uma mudança tecnológica na organização, na gestão do processo de projeto e da produção.

De fato, muitos problemas foram detectados desde a fase projetual, como a quebra de resistências e paradigmas por parte dos responsáveis, ausência de mecanismos de gestão de projetos e dificuldades de integração entre equipes até a utilização do projeto para produção nos canteiros de obras, como resistências ao novo processo, falta de motivação e baixa produtividade.

Em concordância com Barros (1996), é evidente que todos esses problemas não poderiam ser atribuídos exclusivamente ao projeto. Outros elementos, tais como a pré-disposição da obra e sua estrutura organizacional acabam também interferindo nestes resultados.

O foco na implementação de novos processos construtivos, inserido nos projetos para produção de alvenaria, não deve constituir um objetivo pontual de uma atividade isolada, que ocorre no momento da realização dos serviços. Deve ser um objetivo sistêmico e integrado às atividades do ciclo de vida do produto, desde as fases iniciais de concepção, desenvolvimento e produção, para "fazer a evolução atingir o canteiro de obras" (Barros, 1996).

As diretrizes sugeridas propõem a intervenção nos processos de projetação, para a melhoria do potencial de racionalização construtiva nos empreendimentos, dentro dos pressupostos da Engenharia Simultânea de integração e cooperação multidisciplinar.

A engenharia simultânea, aplicada aos projetos para produção no contexto da empresa, é um fator essencial dentro da evolução tecnológica dos processos que o setor de construção de edifícios vem buscando alcançar em sua produção. Entretanto, não podem, porém, ser implementados isoladamente ou simplesmente agregados nas etapas finais de um processo, "sem apoio de procedimentos de execução e controle, sem coordenação de projetos, sem treinamento de pessoal, e, principalmente sem a mudança de posturas hoje vigentes, as quais privilegiam a 
improvisação e a ineficiência na produção e edifícios" (Melhado, 1998), sem estabelecimento de procedimentos executivos e sem envolvimento com as diversas áreas como suprimentos, custos, produção.

\section{REFERÊNCIAS BIBLIOGRÁFICAS}

ANDERY, P. R. P.; VANNI, C.; BORGES, G. Failure analysis applied to design optimisation. In: ANNUAL CONFERENCE OF INTERNATIONAL GROUP FOR LEAN CONSTRUCTION, 8., 2000, Brighton. Proceedings... Brighton: IGLC, 2000.

AQUINO, Janaína P. R. Análise do desenvolvimento e da utilização de projetos para produção de vedações verticais na construção de edifícios. Dissertação (Mestrado em Engenharia) - Departamento de Engenharia de Construção Civil, Escola Politécnica da Universidade de São Paulo, São Paulo, 2004.

BARROS, Mércia Maria. S. Metodologia para implantação de tecnologia construtiva racionalizada na produção de edifícios. Tese (Doutorado em Engenharia) - Escola Politécnica da Universidade de São Paulo, São Paulo, 1996.

BARROS, Mércia Maria. S.; SABBATINI, Fernando H. Diretrizes para o processo de projeto para a implantação de tecnologias construtivas racionalizadas na produção de edifícios. São Paulo: EPUSP, 2003. 24 p. Boletim Técnico da Escola Politécnica da USP, Departamento de Engenharia de Construção Civil, $\mathrm{BT} / \mathrm{PCC} / 172$.

CORRÊA, Cássia V.; ANDERY, Paulo R. P. Avaliação dos resultados da implementação de projetos para produção e racionalização de alvenaria de vedação nos canteiros de obras: um estudo de caso. In: SIMPÓSIO BRASILEIRO DE GESTÃO E ECONOMIA DA CONSTRUÇÃO, 4., 2005, Porto Alegre. Anais... Porto Alegre: NORIE/UFRS, 2005.

CORRÊA, Cássia V. A Aplicação da Engenharia Simultânea na Dinâmica de Elaboração e Implementação de Projetos para a Produção de Alvenaria de Vedação na Construção Civil. Dissertação de Mestrado apresentada ao Curso de Pós-graduação em Construção Civil da Universidade Federal de Minas Gerais. Belo Horizonte, 2006.

FRANCO, Luiz Sérgio. O projeto das vedações verticais: características e a importância para a racionalização do processo de produção. In: SEMINÁRIO TECNOLOGIA E GESTÃO NA PRODUÇÃO DE EDIFÍCIOS: VEDAÇÕES VERTICAIS, 1 , 1998, São Paulo. Anais... São Paulo: EPUSP/PCC, 1998. p. 221-236.

MEDEIROS, J. S; FRANCO L. S. Prevenção de trincas em alvenarias através do emprego de telas soldadas como armadura e ancoragem. São Paulo: Escola Politécnica da USP, Departamento de Engenharia de Construção Civil /EPUSP, 1999. $78 \mathrm{p}$. Texto técnico TT/PCC/22.

MELHADO, Sílvio Burrattino et al. Coordenação de projetos de edificações. 1. ed. São Paulo: O Nome da Rosa, 2005. 115p.

ROMEIRO FILHO, Eduardo. A implantação de sistemas CAD na indústria Aspectos gerenciais, ergonômicos e organizacionais. Dissertação (Mestrado) - COPPE, Universidade Federal do Rio de Janeiro, Rio de Janeiro, 1993. 180 p.

SILVA, Margarete Maria Araújo. Diretrizes para o projeto de alvenarias de vedação. Dissertação (Mestrado em Engenharia) - Departamento de Engenharia de Construção Civil, Escola Politécnica da Universidade de São Paulo, São Paulo, 2003. 